\section{The economics of poisoning: The role of telemedicine and toxicovigilance}

To the Editor: The COVID-19 pandemic has required creative thinking on how to provide healthcare during and after the crisis. The South African lockdown meant limited access to medical services for all communities, making telemedicine even more relevant. ${ }^{[1]}$ For the Poisons Information Helpline (PIH) of the Western Cape, it was business as usual. The PIH takes calls related to poisoning from across the country. The combined service is provided by two poisons information centres (PICs) - at Red Cross War Memorial Children's Hospital and Tygerberg Hospital. It is available 24 hours per day to members of the public and medical personnel. Treatment advice for adults and children (and even animals) is based on the poisons information database, AfriTox, which is created and maintained by the Red Cross Hospital PIC. Weekly clinical toxicology meetings, currently held virtually, discuss interesting PIH cases, using them as a teaching platform, as well as an opportunity to improve the content of AfriTox. Current attendees include members of the PIH (doctors, pharmacists, medical scientists), clinical pharmacologists and clinical pharmacology laboratory staff. Looking to the future, Stellenbosch University, together with the Tygerberg PIC, will be starting a Postgraduate Diploma in Medical Toxicology during 2021 (NQF level 08).

The PIH Specialists in Poisons Information (SPIs) adapt their unique expertise to the clinical presentation of the patient, as well as the medical resources available to the caller. Using the call data that have been collected, the PIH can monitor trends in poisoning and provide toxicovigilance. As is often the case, prevention is the ultimate cure, not only for obvious medical benefits, but also for economic benefits. Recent PIH cases have highlighted the issue of iron supplement ingestion in children. Optimising the care of patients who have iron poisoning requires access to resuscitation measures, specific laboratory investigations and possibly an antidote. The cost of ambulance transfer and hospital admission can be added to this, as well as the psychosocial and economic impact on the caregiver. It is concerning that such a preventable, yet potentially severe poisoning still frequently occurs, when the economic benefits of prevention - simple childproof packaging - surely outweigh the costs of treatment. Similar cost benefits can be seen with paraffin and pesticide poisonings, where childproof storage and improved housing, sanitation and electrification would go a long way to prevent such common paediatric poisonings. ${ }^{[2]}$

The role of emergency telephone services in reducing the cost of poisonings has been proven worldwide. ${ }^{[3,4]}$ The PIH provides such a service, despite limited staffing. As the current social isolation, financial stress and possibly even SARS-CoV-2 result in anxiety and mental health instability, we foresee an increase in the number of patients presenting to emergency departments with self-harming behaviour. As we salute the frontline workers, we too hope to contribute to easing their burden. This can be achieved by keeping persons with minor, mostly paediatric, accidental ingestions at home and ensuring that only those needing hospital care present to facilities. An excellent example is the increase in hand sanitiser ingestions encountered on the PIH during recent months; ${ }^{[5]}$ callers are given clear instructions on when to seek medical help and when staying at home is safe. For patients requiring in-hospital care, the PIH can aid on-site doctors in the management of poisonings, thus enabling appropriate care and referrals in an overburdened healthcare system.

\section{Poisons Information Helpline: 0861555777}

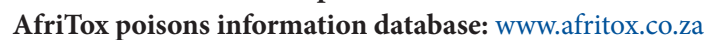

PG Dip Medical Toxicology: http://www.sun.ac.za/english/Lists/ Notices/DispForm.aspx?ID=1531

\section{K Balme, C Stephen, L Curling, F Mohamed}

Red Cross War Memorial Children's Hospital Poisons Information

Centre, Department of Paediatrics and Child Health,

Faculty of Health Sciences, University of Cape Town, South Africa

kate.balme@uct.ac.za

C du Plessis, C Marks, V Pillay-Fuentes Lorente, R van Rensburg, G Voigt

Tygerberg Poisons Information Centre, Division of Clinical

Pharmacology, Department of Medicine, Faculty of Medicine and

Health Sciences, Stellenbosch University, Cape Town, South Africa

\footnotetext{
1. Barit A. Updated guidelines on telemedicine - a step in the right direction. S Afr Med J 2020;110(7):566 https://doi.org/10.7196/SAMJ.2020.v110i7.14816

2. Balme K, Roberts JC, Glasstone M, et al. The changing trends of childhood poisoning at a tertiary children's hospital in South Africa. S Afr Med J 2012;102(3):142-146. https://doi org $/ 10.7196 \% 2$ Fsamj.5149

3. The Lewin Group: Final report on the value of the Poison Center System. Prepared for the American Association of Poison Control Centers (AAPCC), September 2012. https://mnpoison.org/wp-content/ uploads/lewin-report.pdf (accessed 9 September 2020).

4. Elamin MEMO, James DA, Holmes P, et al. Reductions in emergency department visits after primary healthcare use of the UK National Poisons Information Service. Clin Toxicol (Phila) 2018;56(5):342-347. https://doi.org/10.1080\%2F15563650.2017.1390120

5. SABC News. 29 March 2020. https://www.sabcnews.com/sabcnews/keep-hand-sanitisers-out-of-youngchildrens-reach-urges-medical-experts/ (accessed 28 October 2020).
}

S Afr Med J 2020;110(12):1152. https://doi.org/10.7196/SAMJ.2020.v110i12.15296 